\title{
Unmet Need of Family Planning Among Married Women of Reproductive Age in Rural Areas of Manikganj District
}

\author{
*ANMM Uddin ${ }^{1}$, MH Jewel ${ }^{2}$
}

\begin{abstract}
Aims: Introduction: Bangladesh has impressive gains in indicators related to population and family planning. Therefore, the unmet need for family planning should be addressed with utmost importance.

Materials and Methods: A descriptive type of cross sectional study was conducted at four villages of Saturia Upazilla of Manikganj district to find out unmet need of family planning among married women of reproductive age including the status of contraceptive use and obstacles toward using family planning methods. The duration of study was from November 2017 to March 2018. The sample size was 480 in number.
\end{abstract}

Results: In the study, $87.5 \%$ respondents were Muslims. Regarding level of education $18.75 \%$ of the respondents was illiterate, $22.19 \%$ of the respondents completed their primary education and $31.35 \%$ passed the secondary school certificate Examination. Most of the respondents (92.92\%) were housewives. Out of 480 families, $51 \%$ belongs to nuclear family. $23.13 \%$ of the respondents had income below 10,000 Tk. and about $27.50 \%$ had an income more than 20,000 Tk. Among 480 respondents, $42.06 \%$ had 2 living children and about $33.78 \%$ had a single child. $89.17 \%$ of the respondents knew about contraceptive method. OCP was the most preferred method among $57.62 \%$ respondents. $61 \%$ respondents were using contraceptive method. The reason for not using any contraceptive method were fear of side effects (28.03\%), eager to conceive $(13.63 \%)$, and non-co-operative attitude of the husband $(7.58 \%)$. In this study $58.13 \%$ respondents had the knowledge about permanent method of contraception.

Conclusion: Family planning is more of a health necessity than an option. Though family planning program has remarkable success over the past decade, but still there is unmet need.

Key Words: Unmet need, Family planning, Rural women.

\section{Introduction}

Millions of women worldwide would prefer to avoid becoming pregnant either right away or never get pregnant, but are not using any contraception. These women are said to have an "unmet need" for family planning (FP). The concept of unmet need points to the gap between some women's reproductive intentions and their contraceptive behavior ${ }^{1}$. Unmet need can be a powerful concept for FP programs because it is based on the women's own statement in answer to survey questions, and it identifies the group most likely to be interested in contraception, but who do not use it. The challenge is for FP to reach and serve these women. The concept of "unmet need" points to the gap between some women's reproductive intension and their contraceptive behavior ${ }^{2}$. Unmet need does not necessarily mean that Family Planning services are not available. It may also mean lack of information of women regarding the availability of the services, not have sufficient inspirations or confidence and

${ }^{1 *}$ Lt Col Abu Noman Mohammed Mosleh Uddin, Associate Professor of Community Medicine, AFMC, Dhaka

2Mehedi Hasan Jewel, Entomologist, CGO-2, AFMC, Dhaka

*Corresponding Author

Date of submission: 05.06.2018 Date of acceptance: 12.09.2018

AKMMC J 2019; 10(1) : 23-27 
not empowered enough for taking decision regarding using these services ${ }^{3}$.

Being one of the members of the developing countries with low income rate, Bangladesh are facing many problems like literacy, religious barrier, high maternal mortality and high infant mortality and morbidity where high growth rate is the central issue 4 . Population is increasing at the rate of $1.05 \%$ per year. If the population increases at this rate, it will create a great challenge on our economy. To overcome this problem of population explosion, government as well as the NGOs has introduced the concept of family planning among the people $^{5}$. Due to their great achievement in this field, currently the contraceptive prevalence rate (CPR) has increased manifold ${ }^{6}$. The demand of contraceptives has increased so much that in 2007, $80 \%$ of every married women of reproductive age reported having adopted a family planning method at same time compared with only $14 \%$ in 1975 . This is more than a fivefold increase over the past three decades. The current contraceptive prevalence rate is $61.2 \%^{7}$.

Survey research in developing countries estimates that more than 150 million married women of reproductive age have an unmet need for contraception. India has about 31 million women and the majority of African and Middle Eastern countries and in a large number of countries in Asia, Latin America and the Caribbean at least 20\% of married women of reproductive age have an unmet need of contraception ${ }^{8,9}$. In Bangladesh also the unmet need is as higher as $24 \%$. Although achievement of the family planning program is too high, the unmet need is still $23 \%$. It is predicted that the unmet need will grow by $40 \%$ within next 15 years and in this case, the success of population control program will be atstake ${ }^{10}$.

The increase of unmet need every year shows that people are eager to adopt contraceptive methods. The unmet need for family planning should be addressed with utmost importance. Unmet need should also be addressed in family planning program with giving more emphasis, targeting the married youth as the most critical and unaddressed segment of population ${ }^{11}$. At present various active programs on family planning are running over the few decades but considerate number of people yet not motivated to adopt the family planning in their practical life. The study was conducted to determine the unmet need of family planning among rural women including the status of contraceptive use and obstacles toward using family planning methods.

\section{Materials and Methods}

This is a descriptive type of cross sectional study conducted in four villages of Saturia Upazilla of Manikganj district, namely Zannah, Kamta, Gopal nagar and Baliati from November 2017 to March 2018. The study population was the married women of reproductive age (15-49 years). The sample size was 480 married women. Data was collected by face to face interview using close ended semi structured questionnaire. Non-probability purposive sample technique was followed. Data was checked and verified everyday by data collectors for any discrepancy, error or lack of information. The collected data were analyzed by using Microsoft office packages and calculator. Data was presented in the form of tabulation and diagrams after collection and analysis.

\section{Results}

To find out unmet need of family planning among the village women 480 women of reproductive age were included in this study. Most number of respondents $(27.09 \%)$ was in the age group 25-29 years. Below 15 years and above 35 years were only $0.83 \%$ and $26.90 \%$ respectively. Among 480 respondents, $87.5 \%$ were Muslims and $12.5 \%$ were Hindus. $18.75 \%$ were illiterate, $22.50 \%$ were educated up to primary level and $36.46 \%$ up to secondary level. Only $10.42 \%$ and $7.92 \%$ passed SSC and HSC examinations respectively whereas $3.25 \%$ were qualified for graduation and above. On the other hand among the husband of the respondents, illiterate were $20.41 \%$, primary and secondary level qualified were $21.88 \%$ and $26.25 \%$ respectively, SSC and HSC qualified were $13.33 \%$ and $8.13 \%$ respectively, Graduate and above were $9.79 \%$. Most of the respondents $(92.92 \%)$ were housewives. On the other hand, $27.29 \%$ male 
members were involved in business, $21.01 \%$ were daylabourer, $12.71 \% \%$ were farmers, $23.13 \%$ were service holders and $2.71 \%$ were unemployed. About $27.50 \%$ husband's earning was more than $20000 \mathrm{Tk}$. Only $7.71 \%$ husbands earn among less than 5000 Tk. $46.67 \%$ respondents had 5-8 family member, among them $51 \%$ families were nuclear and $49 \%$ families were joint.

In this study most (38.14\%) of the respondents had married life of more than 16 years, $22.29 \%$ had $10-15$ years and $6.45 \%$ had $1-2$ years (Table-I).

Table-I: Distribution of respondents according to duration of marital life $(n=480)$.

\begin{tabular}{lcc}
\hline Duration & Frequency & Percentage \\
\hline 1-2 years & 31 & 6.45 \\
2-5years & 58 & 12.08 \\
5-10 years & 101 & 21.04 \\
10-15 years & 107 & 22.29 \\
$>$ 15 years & 183 & 38.14 \\
\hline
\end{tabular}

$67.89 \%$ of the respondents got the knowledge of contraceptive methods from family planning workers. (Table II)

Table-II: Distribution of respondents according to source of obtaining information about methods $(n=480)$.

\begin{tabular}{lcc}
\hline Source of informant & Frequency & Percentage \\
\hline MBBS doctor & 21 & 5.14 \\
Family planning worker & 277 & 67.89 \\
Teacher/Book & 03 & 0.73 \\
Husband & 19 & 4.66 \\
Relatives & 68 & 16.67 \\
Village Doctor & 08 & 1.96 \\
Mass media & 12 & 2.95 \\
\hline
\end{tabular}

Among respondents, most preferred contraceptive methods was OCP $(57.62 \%)$, others chosen injectable contraceptive $(14.40 \%)$ and condoms (11.42\%) (Table-III).
Table-III: Distribution of respondents according to preferred contraceptive method (Multiple responses Table)

\begin{tabular}{lcc}
\hline Informant & Frequency & Percentage \\
\hline OCP & 348 & 57.62 \\
Injectable contraceptive & 87 & 14.40 \\
Copper T & 36 & 5.96 \\
Norplant & 26 & 4.30 \\
Condoms & 69 & 11.42 \\
Natural & 02 & 0.33 \\
Permanent method & 31 & 5.13 \\
None & 05 & 0.84 \\
\hline
\end{tabular}

In this study $61 \%$ respondents were using contraceptive method during study period while $39 \%$ were non-contraceptive users. $60.99 \%$ of the respondents were eager to use contraceptive method while remaining $39.01 \%$ were not willing to use any method (Fig-1).

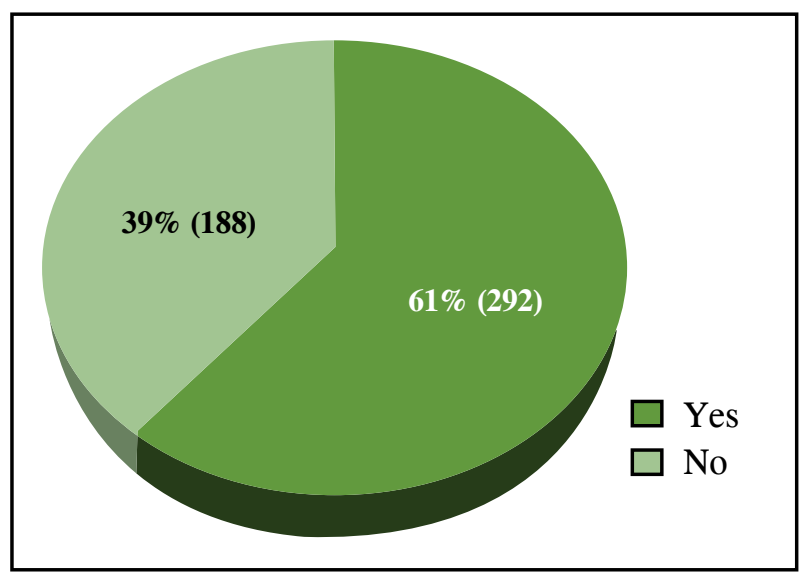

Fig-1: Distribution of respondents according to eagerness to use contraceptive method $(n=480)$

Regarding barriers to use contraceptive, $28.03 \%$ respondents had fear of side effects. Some were eager to conceive (13.63\%) (Table-IV). 
Table-IV: Barriers to use contraceptives among respondents $(\mathrm{n}=132)$.

\begin{tabular}{lcc}
\hline Barriers & Frequency & Percentage \\
\hline Fear of side effect & 37 & 5.14 \\
Eager to conceive & 18 & 67.89 \\
Religious bar & 03 & 0.73 \\
Husband is non co-operative & 10 & 4.66 \\
Ignorance about the method & 21 & 16.67 \\
Not informed by FP worker & 04 & 1.96 \\
Others (Disliking, health issues etc.) & 39 & 2.95 \\
\hline
\end{tabular}

Among the respondents, $58.13 \%$ had the knowledge about permanent method of contraception (Fig-2).

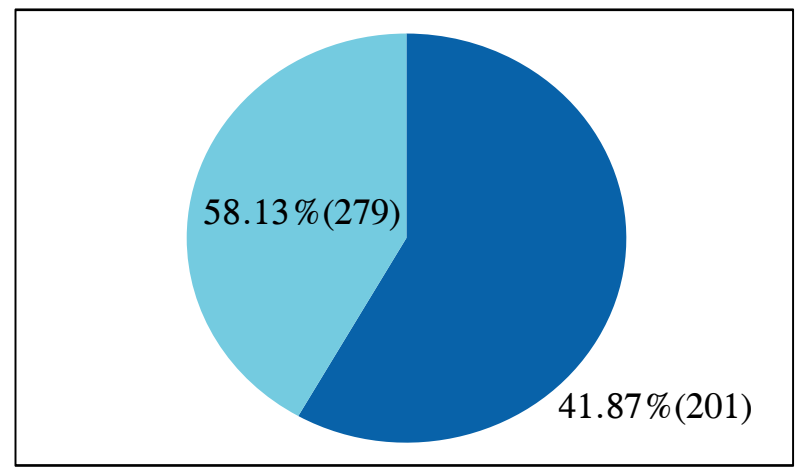

Fig-2: Respondent's knowledge about permanent method of contraception

\section{Discussion}

In this descriptive type of cross sectional study, a total of 480 respondents were interviewed. The objective of the study was to explore the proportion of unmet need of family planning among the married woman of reproductive age. Maximum number of the respondents $(27.09 \%)$ was in the age group 25-29 years. Below 15 years and above 35 years were only $0.83 \%$ and $26.90 \%$ respectively. About half of the families were nuclear type and the rest were joint and extended families. In this study $95 \%$ of the respondents experienced pregnancy at least once during their married life. Study carried out in 2007 in urban slums of Dhaka city, revealed that about one-tenth (8.3\%) had never experienced pregnancy. Rest of the respondents $(91.7 \%)$ had experienced one or more pregnancies ${ }^{12}$.

Most of the respondents (92.92\%) were housewives, Service holders were $2.9 \%$. In another study conducted by Ahmed SM et al. it was found that in rural areas of Bangladesh 50\% woman of age group 15-49 were engaged in poultry and cattle raising, $14.3 \%$ were service holder, $5.5 \%$ had business ${ }^{13}$. The high rate of being housewife among the respondents may be due to location of study area near town and most women did not have scope for poultry and cattle rising.

In this study $30.41 \%$ of the respondents had 1 child, $41.04 \%$ had 2 children and $5.85 \%$ had more than 3 children. In 2007, number of living children among currently married women was $0-9.9 \%, 1-2$ in $42.3 \%$, $3-5$ in $37.5 \% 10$. The difference may be due to higher contraceptive use which is $69.39 \%$ in this study which was $55.8 \%$ at BDHS results ${ }^{10}$. In this study most of the respondents $(95.27 \%)$ had knowledge about contraceptives. A study conducted by Khuda and Howladar in 1998 revealed that knowledge of contraceptive is almost universal among both adolescents and adults in Bangladesh ${ }^{14}$. In this study, $67.89 \%$ the respondents got the knowledge of contraception from FP workers, $16.67 \%$ from relatives, $2.95 \%$ from media. Among respondents, most preferred contraceptive methods was OCP $(57.62 \%)$. Same type of finding was observed in another study conducted by Hanif SMA et al. ${ }^{15}$. This may be due to easy availability and popularity of this particular method. It should be noted that there has been a decline in the use of long acting and permanent methods over the last two decades.

Regarding barrier to use contraceptive methods, $28.03 \%$ respondents kept aside from using contraceptive method in fear of side effects. Some (13.63\%) were eager to conceive, and some $(7.85 \%)$ couldn't use due to husband's non co-operation. In another study, the principal barrier to use contraceptive was fear of side effect in $(46.1 \%)$ cases $^{14}$. Unmet need of family planning in this study was $28.541 \%$. During $1999-2000$ unmet need of family planning was $15 \%$, in 2004 it was $11 \%$, in 2007 it was $18 \% 15$. So, need had increased by $7 \%$ in 3 years from 2004 to 2007 . The reason behind the increasing rate may be the shortage of manpower in the family planning program especially the Family Welfare Assistant (FWA). Education increases receptivity to new technology including awareness and use of contraception. 
Pradhan et al. showed that educated women had desire for fewer children than their less educated counterparts because of incompatibility between formal sector employment and child care. This study also revealed parity decline with increased level of education ${ }^{16}$. Contraceptive use rate also varies according to number of living children. As expected, fewer women use contraception before having their first delivery and after the first child birth, contraceptive use rate increase sharply. There is association between contraceptive use and experience of pregnancy 6 . Appropriate health information and health education is essential to promote contraceptive use which will minimize the unmet need of Family Planning to an acceptable level.

\section{Conclusion}

Improving reproductive health is widely recognized as a key component of social and economic development. Interaction of different factors such as individual, household and community level covariates plays an important role in determining the level of unmet need for family planning. Although success of the family planning program in Bangladesh has been widely acclaimed, many challenges remain and still there is unmet need. It is necessary for the governments to come up with new strategies, which can reduce unmet needs. Moreover, the notable progress in country's family planning program must be continued and strengthened to reach its goal of replacement level fertility.

Conflict of interest: We have no conflict of interest.

\section{References}

1. Casterline JB, Sinding SW. Unmet need for family planning in developing countries and implications for population policy. Popul Dev Rev 2004; 26: 691-723.

2. Westoff CF. The potential demand for family planning. A new measure of unmet need and estimate for 5 lakh American countries. Int Fam Plan Perspect 1998; 14: 4- 6.

3. Cleland J, Bernstein S, Ezeh A et al. Family planning: the unfinished agenda. The Lancet 2006; 368: 1810-1827.
4. Mahmud S, Mahmud W. Rethinking population policy in Bangladesh. CPD- UNFPA Paper Series 24.

5. Kabir A, Islam MN, Chowdhury AA et al. Unmet Need for Family Planning among Married Women: Experience from Rural and Urban Communities. Faridpur Med Coll J 2013; 8(1): 26-30.

6. FerdousiSk, Jabbar MA, Hoque SR. Unmet need of family planning among rural women in Bangladesh. J Dhaka Med Coll 2010; 19(1): 11-15.

7. Islam S, Islam MA, Padmadas SS. High fertility regions in Bangladesh: a marriage cohort analysis. J Biosoc Sci 2010; 42: 705-719.

8. The Unmet Need for Contraception in Developing Countries. www.rand.org/pubs/ research_breifs/ RB5024/index1.html 15th June, 2009.

9. Tuoane M, Madise NJ, Diamond I. Provision of family planning services in Lesotho, International Family Planning Perspectives 2007; 30(2): 77-86.

10. NIPORT, Mitra and Associates, and Macro International. Bangladesh Demographic and Health Surrvey, 2007, preliminary report, Dhaka, Bangladesh.

11. Casterline JB and Sinding SW. Unmet need for family planning in developing countries and implications for population policy. Population and Development Review 2000; 26(4): 691-723.

12. AminM.Unmet Contraceptive Need Among the Eligible Couples in Urban Slum [MPH thesis]. Dhaka: NIPSOM, University of Dhaka. 2007.

13. Ahmed SM, Adams AM, Chowdhury M et al. Socioeconomic development and health seeking behaviour in Bangladesh. Social Science and Medicine 2000; 51: 361-71.

14. Khuda B, Howladar SR. Unmet contraceptive needs and reasons for non-use 1998.

15. Hanif SMA, Bhuiya. Family planning services in a low-performing rural area of Bangladesh: insight from field observation. J Health Pop Nutr 2001; 19: 209-14.

16. Pradhan J, Dwivedi R. Why Unmet Need for Family Planning Remains High in Bangladesh: A Community Level Analysis. J Women's Health Care 2015; 4: 290. 